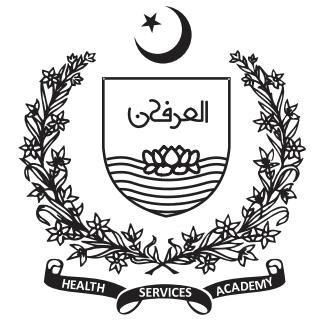

${ }^{1}$ Assistant Professor/ HOD Biochemistry Department, Sialkot College of Physical Therapy, Amin Welfare \& Teaching Hospital, Sialkot, Pakistan.

${ }^{2}$ Professor/ Principal, Sialkot College of Physical Therapy, Chairman Amin Welfare \& Teaching Hospital, Sialkot, Pakistan.

${ }^{3}$ Associate Professor/ HOD/ Programme Director DPT Sialkot College of Physical Therapy, Amin Welfare \& Teaching Hospital, Sialkot, Pakistan.

${ }^{4}$ Assistant Professor Sialkot College of Physical Therapy, Amin Welfare \& Teaching Hospital, Sialkot, Pakistan.

${ }^{5}$ Lecturer PSRD College of Rehabilitation Sciences, Lahore, Pakistan.

${ }^{6}$ Demonstrator Sialkot College of Physical Therapy, Amin Welfare \& Teaching Hospital Sialkot, Pakistan.

Corresponding Author:

Wajida Perveen

Email:

wjda_noor@yahoo.com

\title{
Burnout among Adolescent Population during Covid-19 Lockdown in Sialkot Pakistan
}

Roha Asif ${ }^{1}$, Ijaz Amin², Wajida Perveen³, Misbah Amanat Ali', Umer Ilyas5, Khizra Bashir ${ }^{6}$

\section{Abstract}

Background: To analyze the change in behavioral patterns, its impact, and peer pressure caused by COVID-19 lockdown among the adolescent population.

Methods: It was an observational study with sample size of 443 participants. The study was conducted after ethical approval. Data were collected from different academic institutions in Sialkot, Pakistan using Burnout rating scale. The target population was adolescents of age 13-19 years. Regression analysis was done to find predictor factors mobile use and lockdown on the dependent variable Burnout score. The correlation was applied among mobile phone use, lockdown, and burnout score. IBM software SPSS version 21 was used to analyze data.

Results: Among 443 participants, 305 were female and 138 were male making $68.8 \%$ and $31.2 \%$ respectively. $57.1 \%$ of participants were doing well, $24.8 \%$ became candidates for burnout. In $13.3 \%$ of candidates, the burnout made changes, and for only $4.7 \%$ action should be taken for their health. The correlation coefficient among burnout and using mobile was 0.194 that is highly significant showing a direct positive association between these two variables. The correlation coefficient $(R)$ has a value of -0.222 between burnout and lockdown also showing significance.

Conclusion: Behavioral changes in adolescents concerning burnout due to COVID-19 lockdown was more exaggerated than the actual burnout rate. Behavioral outcome due to COVID-19 lockdown was not that much destructive for adolescent mental health, but only if combined with the other negative traits of the individual.

The protocol of the study was registered on ClinicalTrials.gov wide Identifier: NCT04697030

Keywords: COVID-19 Pandemic, adolescents, burnout, burnout rating scale, mental health, Pakistan

\section{Introduction}

7 he lethal severe acute respiratory syndrome coronavirus 2 (SARS-COV2) which caused the COVID-19 pandemic has affected the lives of children and adolescents globally(1). No doubt there is prominent uncertainty regarding children's and teenage individual's ability to contract, transfer, and spread the virus but it cannot be underestimated(2). Pakistan is one of the lowermiddle-income countries(3) with an estimated population of 350 million, and among them, $34 \%$ are 
children (4). The population of Pakistan stood at 191 million till 2015. Young people aged 10 to 24 years were $32 \%$ of the total population. Very young adolescents (VYA), aged 10-14 years, comprised $11 \%$ of the total population, as did older adolescents (15-19 years), comprised about $10 \%$ of Pakistan's population (5); and according to recent data from Pakistan Bureau of statistics government of Pakistan 2017-2018 the percentage of individuals of age $10-14$ is $12.42 \%$ and individuals of age $15-19$ years is $10.65 \%$ of the total population(6). According to UNICEF, the teenage population is $14.53 \%$ of the total population (7). Due to the lack of a proper health care system, particularly in rural areas, children are prone to many environmental hazards(8).

This virus transmits through social interactions and can be contracted even by a single handshake without showing symptoms for the next two weeks. As the immunity of young individuals is considered strong enough to assume no risk, making that young individual an active carrier of virus spread everywhere. This led to the near-global closure of academic institutes and implementation of lockdown which not only challenged the physical health of individuals and teenagers especially but also their mental health(1) Focusing on the mental challenges given, this pandemic disturbed the daily life of all individuals globally and caused massive disruptions in the lifestyle of teenagers leading to burnout during the COVID 19 lockdown (9). Burnout and anxiety is the common response to any stressful situation and it's the fear of the unknown and it may have multiple consequences (10). Though adolescents are connected with the outside world through smartphones that also played the role in that burnout development somehow apart from its positive aspects $(11,12)$.

The burnout includes physical and emotional burnout; physical burnout refers to the lack of interest in any physical activity to the point of a rebel and the emotional burnout of teenagers refers to a syndrome including features such as behavior changes, thinking change, feeling change, health change leading to stress and other pathological disturbances. Together the external and internal factors lead to overall personality destruction $(13,14)$.

In the last ten months after the outbreak of this COVID 19 the increasing spread of information on television and social media especially concentration only on and around the outbreak and its lethality somehow raised the stress, anxiety, and depression level of individuals globally (15). Nevertheless, this pressure and burden of COVID 19 on teenagers has been neglected along with the effects of this COVID lockdown on the ADLs and IADLs of teenagers who have been living differently before the outbreak. In Pakistan, during this COVID 19 outbreak, no such analysis on the stress levels has been done so far but according to other studies we can relate that the COVID young patients and other individuals showed typhoid like symptoms more frequently with GIT complication and electrolyte imbalance $(16,17)$ which can lead to stress increase as one factor keeping lifestyle change and social media stress aside making the teenager burnout rate higher. Rationale of the study were the analysis of the burnout turnout in teenagers of Sialkot city during the lockdown with the cross-analysis of behavioral patterns and the ratio of actual burnout and stress to the vague feeling and exaggerated expression of being stressed due to many other changes related to gender and age. The basic goals of this study is to determine the incidence of behavioral change among the adolescent population in the Sialkot city of Punjab Pakistan during the lockdown from March $24^{\text {th }}$ to September $15^{\text {th, }} 2020$ and to analyze the difference in the patterns of behavior among the adolescent population towards the lockdown on their life routine.

\section{Methodology}

The study design was a cross-sectional survey with a sample of convenience of 443 participants. A simple random convenient sampling technique was used. The study was conducted after the ethical approval. The data were collected from different institutions of Sialkot Punjab Pakistan within four weeks, right after the COVID lockdown was lifted during October 2020 by visiting schools and academies. Patent and standardized questionnaire Burnout rating scale (BRS) having 0.92 reliability score (18) was used to collect the data, some questions were added and validated. Only adolescent individuals irrespective of gender and whose parents agreed to let them participate in the study were included.

The statistical analysis was done by using the IBM software SPSS version 21. Regression and correlation were applied. Regression analysis was done to find out the predictor factors (independent variables) which were mobile use and COVID lockdown on the dependent variable which was the Burnout score. The correlation was applied among mobile phone use, lockdown, and burnout score. 
The protocol of the study was registered on ClinicalTrials.gov wide Identifier: NCT04697030

\section{Results}

The demographic analysis included age, gender, height, weight, and study year. The total participants of this study were 443 out of which 305 were female and 138 were male (68.8\% and $31.2 \%$ respectively). The mean age of participants was 16.67 years \pm .762 standard deviation. $57.1 \%$ of participants of study were doing well, $24.8 \%$ needed attention as they may became a candidate for burnout. In $13.3 \%$ of candidates, the burnout made changes, and only in $4.7 \%$ respondents, action should be taken immediately because their mental health and well-being were threatened. No impact of age was seen on burnout ( $p$ value was .008).

Pearson correlation test was applied to identify the nature and strength of the relationship among variables. In this study, independent variables were using mobile phones and lockdown should continue or not whereas the dependent variable was burnout total score. It was inferred that the correlation between independent and dependent variables was significant. The correlation coefficient value among burnout and using mobile is 0.194 that is highly significant which shows a significant direct positive association between burnout and using mobile. The co-efficient of correlation (R) has a value of -0.222 between burnout and lockdown should continue which was also significant. This meant that there exists a moderate but significant negative relationship between these two variables.

There was no correlation between burnout and sleeping, online classes, watching TV, and going out of the home. Multiple Regression Analysis to analyze the individual and aggregate impact of Independent on the dependent variable, the multiple regression analysis was performed to confirm whether the data was linear or not or normal and homogeneous. Two independent variables (lockdown and using a mobile phone) can cause $4.9 \%$ and $7.7 \%$ (Adjusted R Square $=.047$ and 0.73 ) variations in burnout score respectively.
Table 1: Total Score BRS

\begin{tabular}{|l|l|c|}
\hline $\begin{array}{c}\text { BRS } \\
\text { Score }\end{array}$ & \multicolumn{1}{|c|}{ Suspected Situation } & $\begin{array}{c}\text { Frequency } \\
\text { /Percent }\end{array}$ \\
\hline $0-15$ & You are doing well & $253(57.1 \%)$ \\
\hline $16-25$ & $\begin{array}{l}\text { Some attention needed, you } \\
\text { may be a candidate }\end{array}$ & $110(24.8 \%)$ \\
\hline $26-35$ & $\begin{array}{l}\text { On the road to burnout, } \\
\text { make changes now }\end{array}$ & $59(13.3 \%)$ \\
\hline $36-50$ & $\begin{array}{l}\text { Take action immediately, } \\
\text { your health and well- } \\
\text { being are threatened }\end{array}$ & $21(4.7 \%)$ \\
\hline & \multicolumn{2}{|c|}{ Total } \\
\hline
\end{tabular}

Table 2: Correlation between Burnout and Mobile use

\begin{tabular}{|l|l|c|c|}
\hline & & $\begin{array}{c}\text { Using } \\
\text { mobile }\end{array}$ & Burnout \\
\hline $\begin{array}{l}\text { Using } \\
\text { Mobile }\end{array}$ & $\begin{array}{l}\text { Pearson } \\
\text { Correlation }\end{array}$ & 1 & $0.194^{* *}$ \\
\cline { 2 - 4 } & $\begin{array}{l}\text { Sig. } \\
(2 \text {-tailed) }\end{array}$ & 0.000 \\
\hline Burnout & $\begin{array}{l}\text { Pearson } \\
\text { Correlation }\end{array}$ & $0.194^{* *}$ & 1 \\
\cline { 2 - 4 } & $\begin{array}{l}\text { Sig. } \\
\text { (2-tailed) }\end{array}$ & 0.000 & \\
\hline
\end{tabular}

** Correlation is significant at the 0.01 level (2-tailed).

Table 3: Correlation between Burnout and Lockdown

\begin{tabular}{|c|c|c|c|}
\hline & & Burnout & Lockdown \\
\hline \multirow[t]{2}{*}{ Burnout } & $\begin{array}{l}\text { Pearson } \\
\text { Correlation }\end{array}$ & 1 & $-.222^{* *}$ \\
\hline & $\begin{array}{l}\text { Sig. } \\
\text { (2-tailed) }\end{array}$ & & .000 \\
\hline \multirow{2}{*}{$\begin{array}{l}\text { Lockdown } \\
\text { should } \\
\text { continuo } \\
\text { or not }\end{array}$} & $\begin{array}{l}\text { Pearson } \\
\text { Correlation }\end{array}$ & $-.222^{* *}$ & 1 \\
\hline & $\begin{array}{l}\text { Sig. } \\
\text { (2-tailed) }\end{array}$ & .000 & \\
\hline
\end{tabular}

** Correlation is significant at the 0.01 level (2-tailed). 


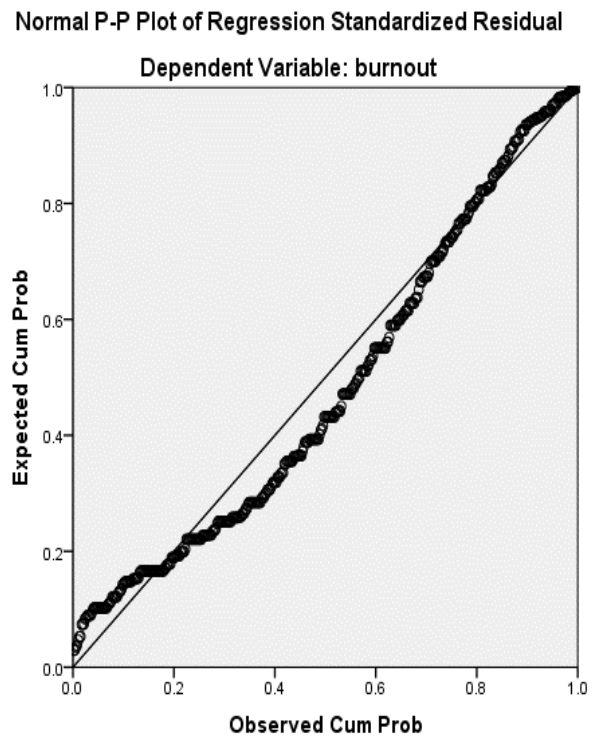

Figure 1: Regression analysis

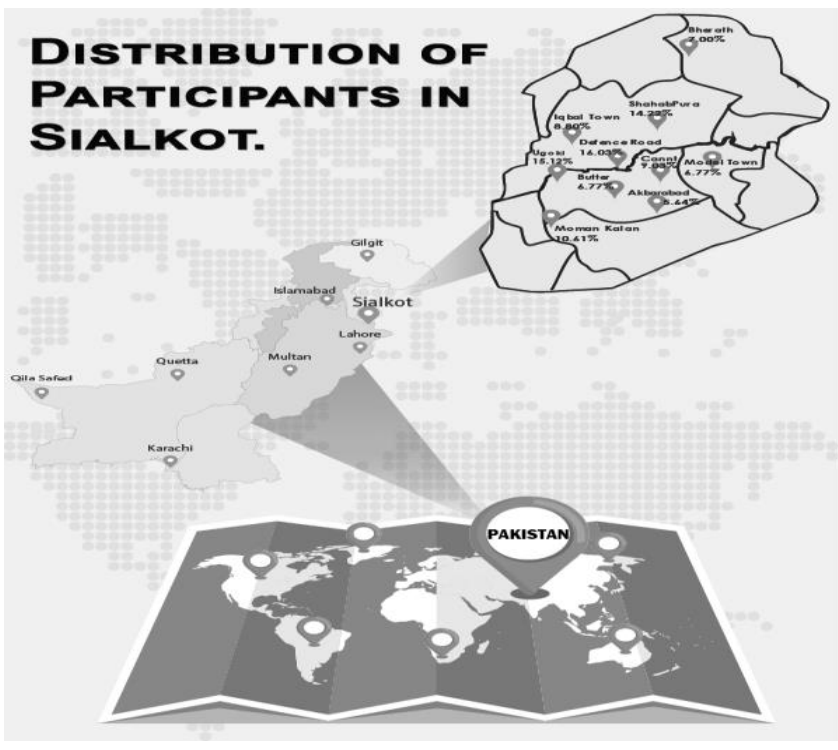

Figure 2: Participant location in Sialkot Pakistan.

\section{Discussion}

Our observational study which was conducted on a particular age group showed that on behavioral change in adolescent population very little effect is caused by the lockdown alone and also it is interpreted that if still, the majority of that population is facing the behavior change then it needs to be checked for the other factors which might or might not prove to be lethal for those individuals in the challenging situation like this pandemic. The result is the observation of the behavioral outcome in the adolescent population of Sialkot city in Pakistan which was unknown earlier whether the stress increase in this age group of the city is due to the only lockdown or are their other factors too which contribute to this increase of stress. As many studies saying that the increase in stress and disturbance in mental health and the overall behavior change in the general population is due to lockdown measures $(4,19)$.

In this study, we found that the lockdown during COVID-19 pandemic alone is not destructive for the mental health of the adolescent population. Unlike it has been found in many studies that isolation, online studies, and stress of pandemic have caused negative effects on the mental health of almost every population. The rate, at which the children and teenagers are infected by the SARS-COV2 virus and transmit, is ambiguous and unanswered. Children and teenagers accounted for 1-3 \% of reported COVID disease across countries and even smaller proportions of severe cases and deaths but the ratio and risk of asymptomatic cases among them are higher which supported the lockdown and in effect challenged the mental health and the healthy active lifestyle of teenagers especially(20). Empirical research says that symptoms of the psychology of the " emotional burnout" process of teenagers include the external factors like the destabilization of learning activities, increased responsibility for performing functions or new ADLs, adverse and pressurized, and confined psychological atmosphere at home, and fear of death. Internal factors also induce the outcome of burnout like less positivity, lack of faith, poor willpower which cannot stop overcoming burnout (13).

According to one study report, it has been cleared that the young individuals unwell with COVID 19 still have the concentrations of the viral genome which confirmed that the role of transmission of COVID 19 through young individuals cannot be underestimated. Viral shedding has even been reported by asymptomatic young individuals (21) No doubt the global community is concerned about coronavirus and this pandemic and studies also showed that it has risky consequences on mental as well as physical health (22). According to another study the impact of this pandemic on global mental health even though has not been measured in detail but the overall analysis through the study of the infected patients show that the hematocrit, calcium, and phosphorus 
levels of patients dropped and the level of circulating cell-free genomic DNA and circulating cell-free mitochondria have shown a delay in the normalization which is the indicator of stress in humans during hemodialysis among patients when in comparison to control groups of same-age individuals gets which showed that the medical isolation and even the simple lockdown isolation increases the stress level of individuals leading to the increased rate of burnout (15).

Another study has shown that the majority of children and teenagers infected by the SARS-COV 2 virus do not show any symptoms and only a few cases unluckily got severely ill. Those who are asymptomatic and were not well proved to be the reason to spread infections along with the invisible changes lead to the raised level of stress in them (23).

Burnout can be explained as the state of emotional, physical, and mental exhaustion that can result from long term involvement in situations and with individuals that are emotionally challenging and demanding. Originally this term is related to the exhaustion connection with workplace stress, especially in the profession that revolves around extensive contact with the people in emotionally challenging situations. In the same way, we can look for the same results and have found that during this COVID 19 pandemic lockdown the same level of burnout and even more mental exhaustion have been observed in teenagers due to the break-in of many activities and due to increase in many different activities new for the daily routine life along with the emotional challenges amidst this lockdown tenure(12).

But not many studies have shown the involvement of lockdown alone in this behavior change, especially in the adolescent population which we highlighted by observing adolescent individuals of Sialkot city of Pakistan leading to the point that the lockdown factor alone can never be lethal or risky for the mental health if no other risks and negative factors are getting out of control and lockdown could be useful enough if taken with positive mindset approaches.

\section{Conclusion}

This study concluded that staying at home, studying from home, online education, and the lifestyle change due to COVID-19 lockdown affected behavioral patterns and burnout rate up to some extent, which may be mistaken for solely the lockdown effects. So our study confirmed that burnout during this lockdown was not that much but may prove destructive enough if combined with the other negative traits of behaviors in the adolescent population.

\section{Limitations}

The limited time frame for data collection with the ongoing fear of the second wave and virus spread was the barrier that stopped us from dwelling deep in this observational study.

\section{Recommendations}

The same observational study can be taken to the level of comparative analysis regarding cities, genders, and even countries. This observational analysis can be used as a first step for the extensive experimental analysis of behavioral changes in the adolescent population during the COVID-19 pandemic

\section{Conflict of interest}

The authors declare that they have no conflict of interest.

\section{Acknowledgment}

We are thankful to the management of Umer Girl's High School, UCAS, University of Sialkot, and the KIPS academy Sialkot campus.

\section{Funding}

This observational study was not funded.

\section{References}

1. Snape MD, Viner RM. COVID-19 in children and young people. Science. 2020;370(6514):286-8.

2. Faust SN, Munro AP. It's Time to Put Children and Young People First During the Global COVID-19 Pandemic. JAMA pediatrics. 2020.

3. Worl Bank classifiaction of countries $n$ the bse of economy world bank website2019-20. Available from: https:// data.worldbank.org/?locations=XN-PK.

4. Organization WH. Mental health and psychosocial considerations during the COVID-19 outbreak, 18 March 2020. World Health Organization, 2020.

5. Sathar Z, Kamran I, Sadiq M, Hussain S. Youth in Pakistan: Priorities, realities and policy responses. 2016.

6. Labour Force Survey 2017-18 (Annual Report) Pakistan: Pakistan Bureau of Statistics; 2-17-18. Available from: http://www.pbs.gov.pk/content/labour-force-survey2017-18-annual-report.

7. Key demographic indicators-Pakistan: UNICEF; 2016. Available from: https://data.unicef.org/country/pak/. 


\section{Burnout among Adolescent Population during Covid-19 Lockdown in Sialkot Pakistan}

8. Majeed MM, Munir A. Pakistan: country report on children's environmental health. Reviews on Environmental Health. 2020;35(1):57-63.

9. Öngür D, Perlis R, Goff D. Psychiatry and COVID-19. Jama. 2020;324(12):1149-50.

10. Saleem Z, Majeed MM, Rafique S, Siqqiqui Z, Ghandhi D, Tariq H, et al. COVID-19 pandemic fear and anxiety among healthcare professionals in Pakistan. 2020.

11. Kamaruddin PSNM, Nawi AM. Smartphone Usage and Pattern on Self-reported Symptoms Among Medical Students in Universiti Kebangsaan Malaysia During the COVID-19 Lockdown. 2020.

12. Slivar B. The syndrome of burnout, self-image, and anxiety with grammar school students. Horizons of Psychology. 2001;10(2):21-32.

13. Vashchenko I, Kondratska L, Nishkur D. Psychological symptomatology of the phenomenon emotional burnout of teenagers: empiric researches. Проблеми сучасної психології. 2017(35):28-43.

14. Joshi G, Sharma G. Burnout: A risk factor amongst mental health professionals during COVID-19. Asian journal of psychiatry. 2020;54:102300.

15. Torales J, O'Higgins M, Castaldelli-Maia JM, Ventriglio A. The outbreak of COVID-19 coronavirus and its impact on global mental health. International Journal of Social Psychiatry. 2020:0020764020915212.
16. $\mathrm{Ng} \mathrm{BH}$, Nik Abeed NN, Abdul Hamid MF, Soo CI, Low HJ, Ban YLA. What happens when we treat the "Typhoid Mary" of COVID-19. Respirology case reports. 2020;8(6):e00604.

17. Zhou X, Li Y, Li T, Zhang W. Follow-up of asymptomatic patients with SARS-CoV-2 infection. Clinical Microbiology and Infection. 2020.

18. Yildırım M, Solmaz F. COVID-19 burnout, COVID-19 stress and resilience: Initial psychometric properties of COVID-19 Burnout Scale. Death Studies. 2020:1-9.

19. Rossi R, Socci V, Talevi D, Mensi S, Niolu C, Pacitti F, et al. COVID-19 pandemic and lockdown measures impact on mental health among the general population in Italy. Frontiers in psychiatry. 2020;11:790.

20. Viner RM, Mytton OT, Bonell C, Melendez-Torres G, Ward J, Hudson L, et al. Susceptibility to SARS-CoV-2 infection among children and adolescents compared with adults: a systematic review and meta-analysis. JAMA pediatrics. 2020.

21. Unchwaniwala $\mathrm{N}$, Ahlquist P. Coronavirus dons a new crown. Science. 2020;369(6509):1306-7.

22. Kumar A, Nayar KR. COVID 19 and its mental health consequences. Journal of Mental Health. 2020:1-2.

23. Srivastava G. The impact of the COVID-19 pandemic on mental health of children and adolescents. 2020. 